\title{
STUDI PREFERENSI KONSUMEN TERHADAP KARAKTERISTIK ORGANOLEPTIK PRODUK CROISSANT DI KOTA MALANG
}

\section{Study of Consumer Preference of Organoleptic Properties of Croissant Products in Malang City}

\author{
Jaya Mahar Maligan*, Yuke Pamelasari \\ Jurusan Teknologi Hasil Pertanian, FTP Universitas Brawijaya Malang \\ Jl. Veteran, Malang 65145 \\ *Penulis Korespondensi, Email: maharajay@gmail.com
}

\begin{abstract}
ABSTRAK
Croissant merupakan salah satu jenis produk pastry yang diminati konsumen sehingga para pelaku industri bakery di Kota Malang harus mengetahui kebutuhan dan keinginan konsumen terhadap croissant untuk meningkatkan minat dan penjualannya. Tujuan dari penelitian ini untuk mengetahui perbedaan persepsi konsumen terhadap atribut organoleptic pada 8 merek croissant yang dijual di Kota Malang. Data uji organoleptik diperoleh dari survey random sampling pada 107 orang responden, kemudian data dianalisis dengan uji nonparametrik Friedman selang kepercayaan 95\%, dilanjutkan uji perbandingan berganda. Hasil penelitian menunjukkan bahwa terdapat perbedaan preferensi konsumen tehadap produk croissant berdasarkan pengujian pada karakteristik organoleptik yang meliputi parameter warna, rasa, aroma, tekstur dan kenampakan croissant.
\end{abstract}

Kata Kunci: Croissant, Preferensi Konsumen, Karakteristik organoleptik.

\begin{abstract}
Croissant is one type of pastry product that consumers are interested in. Therefore, the bakery industry in Malang city must know the needs of consumers towards croissants to increase sales and consumer interest. The purpose of this study was to determine and differences in consumer perceptions of sensory attributes and differences in physical properties of croissant sold in Malang. Organoleptic data were analyzed using Friedman followed by Multiple Comparison Test with 95\% confidence interval. The results showed that there were differences in consumer perceptions of the sensory attributes of croissant products.
\end{abstract}

Keywords: Consumer Preference, Croissant, Organoleptic properties

\section{PENDAHULUAN}

Croissant merupakan salah satu jenis produk pastry yang cukup diminati di Kota Malang. Menurut Gisslen (2005), croissant adalah salah satu produk pastry berbentuk bulan sabit (crescent) atau tanduk (horn) yang dibuat dengan teknik melipat adonan dan mempunyai ciri khas berlapis-lapis. Lapisan yang terbentuk adalah karena adanya shortening yang berada pada masing-masing sisi lapisan adonan pada saat proses melipat adonan.

Berdasarkan hasil survey pendahuluan yang dilakukan pada tahun 2017, dari 50 toko roti yang ada di Kota Malang hanya 11 toko roti yang menjual produk croissant. Oleh karena itu, para pelaku industri bakery harus mengetahui kebutuhan dan keinginan konsumen terhadap croissant untuk meningkatkan penjualan dan minat konsumen. Tujuan dari penelitian ini adalah untuk mengetahui dan menganalisis perbedaan preferensi konsumen terhadap atribut sensori dan perbedaan sifat fisik produk croissant yang dijual di Kota Malang. 


\section{BAHAN DAN METODE}

\section{Bahan}

Bahan utama untuk penelitian ini adalah 8 merek croissant (plain) tanpa topping yang diperoleh dari 8 toko roti di Kota Malang yaitu HLB, BKM, BDS, DNK, FPB, JKC, HLB dan SBC. Bahan pendamping yang dibutuhkan untuk pengujian organoleptik adalah air mineral $240 \mathrm{ml}$ untuk menetralkan rasa di mulut (palate cleanser) dan tisu.

\section{Alat}

Alat yang digunakan untuk penelitian ini dibedakan menjadi alat untuk analisis sensori. Alat yang digunakan untuk analisis sensori adalah garpu, alas sampel, kertas A4, bollpoint, meja, kursi, dan kuisioner uji.

\section{Penentuan Sampel dan Responden}

Sampel yang digunakan pada penelitian kali ini merupakan croissant dengan rasa plain tanpa topping. Berdasarkan survey pendahuluan, dari 11 toko roti yang menjual croissant di Kota Malang hanya ada 8 toko roti yang produknya dapat dijadikan sampel. Responden merupakan masyarakat Kota Malang berjenis kelamin laki - laki dan perempuan dengan rentang usia 17 - 30 tahun dan merupakan konsumen dari produk croissant yang mengkonsumsi croissant setidaknya 6 bulan sekali. Responden didapatkan berdasarkan hasil survey online dan wawancara yang sesuai dengan persyaratan dan bersedia mengikuti pengujian organoleptik, yaitu berjumlah sebanyak 107 orang.

\section{Pengambilan Data}

Data penelitian ini diambil berdasarkan hasil uji organoleptik yang telah dilakukan. Pengujian organoleptik dilakukan menggunakan uji hedonik (kesukaan). Parameter yang digunakan dalam uji hedonik meliputi warna, kenampakan, aroma, rasa, dan tekstur.

\section{Analisis Data}

Analisis data fisik dilakukan menggunakan metode ANOVA General Linear Model (GLM) pada Minitab 18 selang kepercayaan 95\% dilanjutkan dengan uji Tukey. Metode uji organoleptik yang digunakan adalah Hedonic Scale Scoring dengan uji nonparametrik Friedman pada Minitab 18 selang kepercayaan 95\% dilanjutkan dengan uji lanjut Perbandingan Berganda.

\section{HASIL DAN PEMBAHASAN}

\section{Karakteristik Responden}

Karakteristik umum responden untuk penelitian ini adalah masyarakat Kota Malang yang sesuai dengan syarat yang telah ditentukan dan bersedia untuk melakukan pengujian sensoris. Responden yang digunakan dalam penelitian kali ini berjumlah 107 responden. Data karakteritik responden dapat dilihat pada Tabel 1.

Tabel 1 menunjukkan bahwa responden paling banyak merupakan responden dengan usia 22 tahun dengan jumlah 26 orang dan responden paling sedikit merupakan responden dengan usia 19 dan 29 tahun dengan jumlah masing-masing 2 orang. Menurut Novak (2012), perempuan berumur 40 hingga 50 dan laki-laki berumur 50 hingga 60 akan mengalami penurunan fungsi indra perasa karena jumlah dan ukuran dari kuncup pengecap berkurang. Penurunan fungsi indra penciuman akan terjadi setelah manusia mencapai umur 70 tahun, hal ini akan mengakibatkan hilangnya selera makan. Responden paling banyak merupakan responden perempuan dengan jumlah 73 orang dan sisanya merupakan responden laki-laki dengan jumlah 34 orang. Menurut Michon et al. (2009), secara keseluruhan perempuan memiliki sensitivitas terhadap rasa dan bau yang lebih tinggi dari pada laki-laki. Berdasarkan frekuensi kunjungan, responden paling banyak merupakan responden yang mengunjungi toko roti dengan frekuensi 2 minggu sekali dengan jumlah 36 orang. Berdasarkan frekuensi 
konsumsi, responden paling banyak merupakan responden yang mengkonsumsi croissant dengan frekuensi 1 bulan sekali dengan jumlah 49 orang.

Tabel 1. Karakteristik Responden

\begin{tabular}{cccc}
\hline Karakteristik & Jumlah & Karakteristik & Jumlah \\
\hline Usia & \multicolumn{3}{c}{$\begin{array}{c}\text { Frekuensi Mengunjungi } \\
\text { Toko Roti }\end{array}$} \\
18 & 7 & 1 minggu lebih dari 1 kali & 11 \\
19 & 2 & 1 minggu sekali & 13 \\
20 & 10 & 2 minggu sekali & 36 \\
21 & 24 & 1 bulan sekali & 32 \\
22 & 26 & 2 bulan sekali & 15 \\
23 & 7 & Frekuensi Konsumsi & \\
24 & 8 & Croissant & 8 \\
25 & 5 & 1 minggu sekali & 24 \\
26 & 4 & 2 minggu sekali & 49 \\
27 & 3 & 1 bulan sekali & 26 \\
28 & 5 & & \\
29 & 2 & & \\
30 & 4 & & \\
Jenis Kelamin & & & \\
Laki - laki & 34 & & \\
Perempuan & 73 &
\end{tabular}

\section{Tingkat Kesukaan Terhadap Warna}

Rerata kesukaan responden terhadap warna 8 sampel croissant berkisar antara 3,00 hingga 3,73 (cukup suka). Rerata nilai kesukaan responden terhadap warna croissant dapat dilihat pada Tabel 2.

Tabel 2. Perbedaan Rerata Kesukaan Terhadap Warna Antar Sampel

\begin{tabular}{cc}
\hline Sampel & Rerata Kesukaan Terhadap Warna \\
\hline SBC & $3,00 \pm 1,17 \mathrm{a}$ \\
BDS & $3,26 \pm 1,03 \mathrm{ab}$ \\
JKC & $3,31 \pm 1,12 \mathrm{ab}$ \\
FPB & $3,38 \pm 1,05 \mathrm{ab}$ \\
BKM & $3,40 \pm 0,83 \mathrm{ab}$ \\
DNK & $3,45 \pm 0,90 \mathrm{ab}$ \\
NYB & $3,46 \pm 0,99 \mathrm{ab}$ \\
HLB & $3,73 \pm 0,87 \mathrm{~b}$ \\
\hline
\end{tabular}

.Hasil analisis statistik Friedman menunjukkan bahwa perbedaan sampel croissant berpengaruh nyata terhadap tingkat kesukaan responden pada warna croissant. Responden memilih sampel HLB sebagai sampel dengan rerata nilai warna tertinggi. Responden lebih menyukai warna croissant seperti warna sampel HLB yang lebih kuning keemasan dan cerah daripada sampel lainnya. Hal ini sesuai dengan pendapat Coutelle (2014) bahwa croissant berwarna coklat keemasan. Sampel dengan nilai rerata warna terendah yang dipilih oleh responden adalah sampel SBC. Responden kurang menyukai warna Sampel SBC yang lebih gelap dan lebih coklat dari sampel lainnya karena kemungkinan dianggap gosong. 


\section{Tingkat Kesukaan Terhadap Aroma}

Rerata kesukaan terhadap aroma 8 sampel croissant berkisar antara 2,70 (tidak suka) hingga 3,51 (cukup suka). Rerata nilai kesukaan responden terhadap aroma croissant dapat dilihat pada Tabel 3.

Tabel 3. Perbedaan Rerata Kesukaan Terhadap Aroma Antar Sampel

\begin{tabular}{cc}
\hline Sampel & $\begin{array}{c}\text { Rerata Kesukaan Terhadap } \\
\text { Aroma }\end{array}$ \\
\hline FPB & $2,70 \pm 0,98 \mathrm{a}$ \\
BDS & $2,78 \pm 0,90 \mathrm{a}$ \\
SBC & $2,83 \pm 0,97 \mathrm{abc}$ \\
JKC & $3,03 \pm 1,31 \mathrm{abc}$ \\
NYB & $3,23 \pm 1,06 \mathrm{bcd}$ \\
HLB & $3,39 \pm 0,94 \mathrm{~cd}$ \\
DNK & $3,48 \pm 1,05 \mathrm{~cd}$ \\
BKM & $3,51 \pm 0,91 \mathrm{~d}$ \\
\hline
\end{tabular}

Hasil analisis statistik Friedman menunjukkan bahwa perbedaan sampel croissant berpengaruh nyata terhadap tingkat kesukaan responden pada aroma croissant. Responden memilih sampel BKM sebagai sampel dengan rerata nilai aroma tertinggi. Sampel dengan nilai rerata aroma terendah yang dipilih oleh responden adalah sampel FPB. Perbedaan persepsi konsumen terhadap aroma sampel dapat dikarenakan perbedaan sensitivitas indra penciuman dan tingkat kesukaan responden terhadap bahan yang digunakan dalam pembuatan croissant. Menurut Boesveldt dan Graaf (2017), indera penciuman memainkan peran utama dalam perilaku makan seseorang yang telah didemonstrasikan bahwa paparan bau dapat merangsang nafsu makan. Namun, pengaruh aroma pada pemilihan makanan dapat bergantung pada kesadaran, intensitas aroma, dan berdasarkan ciri - ciri kepribadian dari konsumen.

\section{Tingkat Kesukaan Terhadap Rasa}

Rerata kesukaan terhadap rasa 8 sampel croissant berkisar antara 2,68 (tidak suka) hingga 3,69 (cukup suka). Rerata nilai kesukaan responden terhadap rasa croissant dapat dilihat pada Tabel 4.

\begin{tabular}{cc} 
Tabel 4. Perbedaan Rerata Kesukaan Terhadap Rasa Antar Sampel \\
\hline Sampel & Rerata Kesukaan Terhadap Rasa \\
\hline BDS & $2,68 \pm 0,90 \mathrm{a}$ \\
SBC & $2,78 \pm 1,13 \mathrm{ab}$ \\
JKC & $3,08 \pm 1,35 \mathrm{abc}$ \\
DNK & $3,15 \pm 1,00 \mathrm{abc}$ \\
FPB & $3,16 \pm 1,10 \mathrm{bcd}$ \\
HLB & $3,27 \pm 1,03 \mathrm{~cd}$ \\
BKM & $3,49 \pm 1,01 \mathrm{~cd}$ \\
NYB & $3,69 \pm 1,07 \mathrm{~d}$ \\
\hline
\end{tabular}

Hasil analisis statistik Friedman menunjukkan bahwa perbedaan sampel croissant berpengaruh nyata terhadap tingkat kesukaan responden pada rasa croissant. Responden memilih sampel NYB sebagai sampel dengan rerata nilai rasa tertinggi. Hal ini dapat dikarenakan sampel NYB dianggap memiliki rasa yang lebih manis jika dibandingkan dengan semua sampel dan dianggap sesuai dengan persepsi responden mengenai croissant. Sampel 
dengan nilai rerata rasa terendah yang dipilih oleh responden adalah sampel BDS. Hal ini dapat dikarenakan sampel BDS dianggap memiliki rasa yang kurang sesuai dengan persepsi responden mengenai croissant. Menurut Woods (1998) rasa merupakan sensasi yang terjadi ketika makanan atau minuman diletakkan pada mulut dan sensasi keseluruhan dari rasa merupakan hasil dari kombinasi respon dari reseptor yang ada pada lidah, mulut, tenggorokan, dan hidung.

\section{Tingkat Kesukaan Terhadap Tekstur}

Rerata kesukaan terhadap tekstur 8 sampel croissant berkisar antara 2,98 (tidak suka) hingga 3,45 (cukup suka). Rerata nilai kesukaan responden terhadap tekstur croissant dapat dilihat pada Tabel 5.

Tabel 5. Perbedaan Rerata Kesukaan Terhadap Tekstur Antar Sampel

\begin{tabular}{cc}
\hline Sampel & Rerata Kesukaan Terhadap Tekstur \\
\hline SBC & $2,98 \pm 1,00 \mathrm{a}$ \\
BDS & $3,15 \pm 1,13 \mathrm{ab}$ \\
BKM & $3,22 \pm 1,06 \mathrm{ab}$ \\
FPB & $3,24 \pm 1,10 \mathrm{ab}$ \\
DNK & $3,30 \pm 0,97 \mathrm{ab}$ \\
JKC & $3,36 \pm 1,01 \mathrm{ab}$ \\
HLB & $3,36 \pm 0,96 \mathrm{ab}$ \\
NYB & $3,45 \pm 0,98 \mathrm{~b}$ \\
\hline
\end{tabular}

Hasil analisis statistik Friedman menunjukkan bahwa perbedaan sampel croissant berpengaruh nyata terhadap tingkat kesukaan responden pada tekstur croissant. Responden memilih sampel NYB sebagai sampel dengan rerata nilai tekstur tertinggi. Hal ini dapat dikarenakan sampel NYB dianggap memiliki tekstur yang sesuai dengan persepsi responden mengenai croissant. Sampel dengan nilai rerata tekstur terendah yang dipilih oleh responden adalah sampel SBC. Hal ini dapat dikarenakan sampel SBC dianggap memiliki tekstur yang kurang sesuai dengan persepsi responden mengenai croissant. Menurut Watts (2009), pastry berbeda dengan roti karena memiliki kandungan lemak yang lebih tinggi sehingga teksturnya rapuh dan renyah. Beranbaum (2003) menjelaskan bahwa pencampuran dan pengulenan adonan yang berlebihan dapat menyebabkan kulit croissant menjadi keras. Croissant yang dibuat dengan baik memiliki kulit yang renyah dan bagian dalam yang rapuh dan lembut.

\section{Tingkat Kesukaan Terhadap Kenampakan}

Rerata kesukaan terhadap kenampakan 8 sampel croissant berkisar antara 2,71 (tidak suka) hingga 3,56 (cukup suka). Rerata nilai kesukaan responden terhadap kenampakan croissant dapat dilihat pada Tabel 6.

Tabel 6. Perbedaan Rerata Kesukaan Terhadap Kenampakan Antar Sampel

\begin{tabular}{cc}
\hline Sampel & $\begin{array}{c}\text { Rerata Kesukaan Terhadap } \\
\text { Kenampakan }\end{array}$ \\
\hline DNK & $2,72 \pm 0,98 \mathrm{a}$ \\
SBC & $2,71 \pm 1,21 \mathrm{ab}$ \\
BDS & $3,04 \pm 1,08 \mathrm{abc}$ \\
NYB & $3,22 \pm 1,29 \mathrm{bc}$ \\
JKC & $3,4 \pm 1,09 \mathrm{c}$ \\
BKM & $3,47 \pm 0,99 \mathrm{c}$ \\
FPB & $3,47 \pm 0,99 \mathrm{c}$ \\
HLB & $3,56 \pm 1,09 \mathrm{c}$ \\
\hline
\end{tabular}


Hasil analisis statistik Friedman menunjukkan bahwa perbedaan sampel croissant berpengaruh nyata terhadap tingkat kesukaan responden pada kenampakan croissant. Menurut Campo, et al (2017), pendapat seseorang mengenai kenampakan suatu produk dipengaruhi oleh warna dan bentuk dari produk tersebut. Responden memilih sampel HLB sebagai sampel dengan rerata nilai kenampakan tertinggi karena dianggap memiliki warna, bentuk, dan ukuran yang sesuai dengan persepsi responden mengenai croissant. Sampel dengan nilai rerata kenampakan terendah yang dipilih oleh responden adalah sampel SBC karena dianggap memiliki warna, bentuk, ukuran dan tekstur yang kurang sesuai dengan persepsi responden mengenai croissant. Menurut Coutelle (2014), croissant berbentuk seperti bulan sabit, terlihat renyah, berwarna coklat keemasan, dan memiliki permukaan yang tidak halus.

\section{Tingkat Kesukaan Secara Keseluruhan}

Rerata kesukaan terhadap keseluruhan parameter organoleptik ke-8 sampel croissant berkisar antara 2,86 (tidak suka) hingga 3,46 (cukup suka). Rerata nilai kesukaan responden secara keseluruhan pada produk croissant dapat dilihat pada Tabel 7.

Tabel 7. Rerata Kesukaan Secara Keseluruhan Terhadap Parameter Organoleptik Antar Sampel

\begin{tabular}{cc}
\hline Sampel & Rerata Kesukaan Secara Keseluruhan \\
\hline HLB & 3.46 \\
BKM & 3.42 \\
NYB & 3.41 \\
JKC & 3.24 \\
DKN & 3.22 \\
FPB & 3.19 \\
BDS & 2.98 \\
SBC & 2.86 \\
\hline
\end{tabular}

Berdasarkan Tabel 7 dapat diketahui bahwa secara keseluruhan dari semua parameter organoleptik (warna, rasa, aroma, tekstur dan kenampakan) yang diuji, kesukaan responden paling tinggi adalah pada sampel HLB (3.46) dan yang paling rendah adalah sampel SBC (2.86).

\section{SIMPULAN}

1. Hasil penelitian menunjukkan bahwa preferensi konsumen berbeda nyata terhadap karakteristik organoleptic meliputi paramater warna, aroma, rasa, tekstur dan kenampakan 8 produk croissant yang di jual di Kota Malang.

2. Tingkat kesukaan responden paling tinggi adalah pada sampel HLB (3.46) dan yang paling rendah adalah sampel SBC (2.86), dimana sampel HLB mempunyai keunggulan pada parameter warna dan kenampakan sedangkan sampel SBC mempunyai kelemahan pada parameter warna dan tekstur.

\section{DAFTAR PUSTAKA}

Beranbaum, R. 2003. The Bread Bible. W. W. Norton \& Company, Inc. Manhattan.

Boesveldt, S., \& de Graaf, K. 2017. The Differential Role of Smell and Taste for Eating Behavior. Perception, 46(3-4), 307-319. 
Campo, R., Loporcarco, G., Baldassarre, F. 2017. The Effects of Food Aesthetic on Consumers. Visual Stimuli and Food Marketing. DIEM: Dubrovnik International Economic Meeting (Vol. 3, No. 1, pp. 553-565).

Coutelle, D. 2014. The Perfect Croissant. Agate Publishing. Chicago.

Gisslen, W. 2002. Professional Baking $4^{\text {th }}$ Ed. John Wiley and Sons. USA

Lugito. A. 2013. Karakteristik Fisikokimia dan Organoleptik Puff Pastry dengan Subtitusi Tepung Kacang Merah. Widya Mandala Catholic University. Surabaya.

Michon, C., O'Sullivan, M. G., Delahunty, C. M., dan Kerry, J. P. 2009. The Investigation of Gender-Related Sensitivity Differences in Food Perception. Journal of Sensory Studies 24 (2009) 922-937. Wiley Periodicals, Inc

Novak, M. 2012. Issues in Aging. Routledge. New York.

Provost, J. J., Colabroy, K. L., Kelly, B. S., dan Wallert, M. A. 2016. The Science of Cooking: Understanding the Biology and Chemistry Behind Food and Cooking. John Wiley \& Sons, Inc. New Jersey.

Ramadhani, F. 2017. Pengaruh Jenis Tepung dan Penambahan Perenyah Terhadap Karakteristik Fisikokimia dan Organoleptik Kue Telur Gabus Keju. Jurnal Pangan dan Agroindustri Vol.5 No.1:38-47, Januari 2017

Ronzio, R. 2003. The Encyclopedia of Nutrition and Good Health. Facts On File, Inc. New York.

Stadelman, W. J. dan Cotterill, O. J. 2013. Egg Science and Technology, Fourth Edition. The Haworth Press, Inc. New York.

Vaclavik, V., dan Christian, E. 2008. Essentials of Food Science. Springer Science+Business Media, LLC. New York.

Watson, T. 2011. BIRT Croissants Information Sheet. Baking Industry Reasearch Trust. New Zealand.

Watts, P. 2009. Where Food and People Meet. Xilbris Corporation. Bloomington.

Woods, M. P. (1998). Symposium on 'Taste, Flavour and Palatability' Taste and Flavour Perception. Proceedings of the nutrition society, 57(4), 603-607. 